\title{
A Back-up Quarterback View of Mezzanine Finance
}

\author{
Antonio Mello \\ Erwan Quintin* \\ Wisconsin School of Business \\ Wisconsin School of Business
}

February 10, 2015

\author{
Preliminary and incomplete
}

\begin{abstract}
Mezzanine finance is ubiquitous. Traditional arguments describe the purpose of Mezzanine debt as completing the market, specifically as "plugging" a financing gap. According to that view, intermediate seniority claims add to the available menu of risk-return combinations hence helps cater to the needs of heterogeneous investors and generates additional sources of capital for productive investment projects. We describe a completely different yet equally fundamental role for Mezzanine debt which creates economic value even in a world where all investors are homogenous and risk-neutral. According to our theory, Mezzanine financiers serve as substitute managing agents - "back-up quarterbacks" of sorts - ready to replace the original borrower when the project underperforms. They enable senior borrowers to provide incentives to the original agent without resorting to inefficient punishment such as foreclosing on the project even when its NPV as a going-concern remains positive. The fact that Mezzanine lenders tend to be industryspecialists while senior borrowers tend to be traditional intermediaries, we argue, constitutes direct evidence that Mezzanine stakeholders provide the expertise senior lending need to efficiently mitigate agency frictions.
\end{abstract}

Keywords: Mezzanine, Optimal security design, Asymmetric information JEL codes: D47; D82

*Email: amello@bus.wisc.edu and equintin@bus.wisc.edu. We wish to thank Scott Gibbel for his research assistance, Timothy Riddiough, Mark Ready, Cyril Monnet and Tom McCahill for their generous comments. 


\section{Introduction}

Work on the capital structure of firms is founded on Modigliani and Miller's (MM, 1958) seminal article. They establish that when capital markets are efficient and frictionless (meaning no taxes and bankruptcy costs), the value of a firm is independent of how the company is financed. Their irrelevance proposition reduces the value of a company to the valuation of its assets in place. Although the relative proportions of debt and equity can vary in the firm's balance sheet, in MM's logic the weighted average cost of capital (WACC) stays constant. The notion embeds a direct relation between risk and expected return, so when a firm relies more on debt financing, it automatically bears a higher cost on its equity capital, a tradeoff that is suitably captured in an asset pricing model such as the capital asset pricing model (CAPM).

In practice of course there are frictions that alter the irrelevance result of ModiglianiMiller. Miller (1977) and Brennan and Schwartz (1978) propose a formulation based on the tax benefits of debt and the costs of bankruptcy. In the tradeoff theory taxes make debt cheaper relative to equity, but debt introduces the risk of default, therefore with costly default, the optimal capital structure occurs when the marginal tax shield benefit of debt equates the marginal expected loss from bankruptcy.

The tradeoff theory is simple, intuitive, and able to generate plausible levels of debt and reasonable credit risk spreads 11 However, it ignores that the capital structure is a byproduct of the firm's investment and dependent on the firm's earnings. Investment and earnings generation are not done by robots, but the product of decisions made by those operating the firm's assets. In modern firms, there is separation of ownership and control. Investors own the firm and entrepreneurs/managers control the assets. Each group has its own preferences, objectives, and constraints. More important, the ability to operate the assets is a skill that gives the entrepreneur/manager a prominent role in the firm as well as access to private information.

One consequence of the separation of ownership and control translates into the opportunity for the entrepreneur/manager to divert part of the firm's earnings for his own private benefit. Given the entrepreneur's inability to commit to satisfy the payments pledged, investors demand protective measures, such as covenants and collateral, and provide incentives, in the form of rewards, such as the vow of future funding, as in Bolton and Scharfstein (1990),

\footnotetext{
${ }^{1}$ see Goldstein et al. (2001).
} 
or in equity continuation value, or in the form of penalties, such as the threat of extinguishing the firm, as in Hart and Moore $(1994,1998)$, or the threat of replacing the entrepreneur, as in Spear and Wang (2005).

Recent models by DeMarzo and Fishman (2007), DeMarzo and Sannikov (2006) and Biais et. al. (2007) attempt to provide a way of combining the firm's choice of capital structure with a contract that creates the right incentives for the entrepreneur/manager operating the firm's assets. Their optimal capital structure is surprisingly simple with straight debt, equity and a line of credit that is used to overcome temporary liquidity constraints. In their model, investors decide to liquidate the firm after the entrepreneur/manager reports sufficiently low earnings. This happens even when all parties recognize that the report is not strategic and liquidation is inefficient.

Liquidation can be particularly costly in complex projects. Complex projects involve a multitude of different interconnected tasks and activities that need to be managed with a high level of technical precision, accomplished under tight deadlines and in a changing and often ambiguous environment. ${ }^{2}$ In such projects the managerial skills of the entrepreneur/manager are the most important ingredient for success. Having an effective manager is critical, and although there are methods for screening his quality, such methods are never a guarantee. The reason lies in the very nature of complex projects, where normally there is little precedence for dealing with the technical and design problems, and unforeseen circumstances make it hard to anticipate whether people are aligned or understand what needs to be done. Therefore, in complex projects contract renegotiation often provides inferior outcomes. The solution in Bolton and Scharfstein (1990) of having a dispersed debt ownership structure to mitigate the threat of default by the operator is not feasible, because the lack of coordination associated with dispersion gives undue bargaining power to the project's operator. The alternative of writing covenants in the expectation of future renegotiation suggested in Gârleanu and Zwiebel (2009) and documented in Roberts and Sufi (2009) is at best of limited success. Repeated renegotiation with an operator who fails to deliver frequently is as bad as liquidation.

When the human capital of the operator is the key element to the generation of earnings and the success of a complex project and it is difficult to search and find replacements ex-post, the design of the capital structure needs to reflect the parties' anticipation of a possible failure involving the removal of the manager. In this paper we postulate that the optimal capital structure of complex projects incorporates mezzanine finance. Mezzanine is a layer of finance

\footnotetext{
${ }^{2}$ See Regmington and Pollack (2008).
} 
that is sandwiched between senior debt and lower priority equity. What makes mezzanine special are the investors providing the funds. These are investors with the skills to step in and manage the project in the event the designated manager fails to perform and needs to be removed.

In this paper we provide a model that shows that mezzanine finance is not just another tranche of financial capital that fills the gap when additional sources of senior capital are not enough to fund the entire project. The key to understand mezzanine finance is to see that it is a security that renders inseparable specific human capital and financial capital. The mezzanine tranche is state contingent: If the designated manager performs well, mezzanine works as regular debt. However, if after the realization of poor earnings the incumbent manager might as well be replaced, mezzanine becomes equity and mezzanine investors step in and replace the manager. Hence, mezzanine finance is not simply a contract with a built-in feature that converts debt into equity upon poor performance of the current manager, which is often the case in the event of a debt restructuring. The key feature of mezzanine finance is the standby managerial skill available if and when it becomes optimal to remove the current manager.

Realistically, sourcing additional capital following significant underperformance presents great difficulty, because after reporting poor earnings a more indebted firm faces the cost of debt overhang analyzed in Myers (1977), and a serious adverse selection cost studied in Myers and Majluf (1984). The way to circumvent ex-post contracting problems involves a two-way commitment between the senior creditors and mezzanine investors: Senior creditors agree not to collect debt and enforce liens (i.e., they commit to continue the project), and mezzanine investors commit to step in and run the project upon the removal of the designated manager by the senior creditors. The efficiency the solution lies in the fact that with limited commitment, it is important to simplify or even avoid renegotiation and liquidation. Without mezzanine finance, a high risk project should be funded by a capital structure designed to make restructuring simple. With mezzanine finance, existing claimholders do not agree to restructure the debt after default; instead, they agree to "restructure" the manager and keep the debt virtually intact.

We show that the optimal contract requires the commitment of mezzanine investors to coinvest in the project, and that their claim is debt with a trigger to convert into equity if they have to step in and manage the project. The requirement by the senior creditors that mezzanine investors put down capital up-front makes the mezzanine contract different from the 
alternative course of action of searching for replacement if later the project's operator fails. In return, senior creditors agree ex-ante to not exercise any liens they have on the assets. Without such commitments by both parties the contract would not be different from the typical contract where upon termination, senior creditors fire the current entrepreneur/manager and hire a new agent.

Contrary to most models of the firm that assume a simple capital structure, recent work by Roberts and Sufi (2009) and Rauh and Sufi (2010) has shown that firms have elaborated capital structures, with different layers of debt and quasi-equity securities. The authors find that riskier firms have more complex debt structures. Our model provides one reason for capital structure complexity, and does so while explaining the logic for mezzanine finance, an intermediate source of financial capital that is inalienable from the unique role human capital plays in the project. This also explains another interesting dichotomy between regular debt and mezzanine debt. In regular debt, lenders often require the loan to be collateralized by the assets. Mezzanine debt, on the other hand, is less concerned with asset collateralization, and instead requires security of the holding management company, which concentrates all the control rights to the project. The presence of mezzanine finance in the capital structure also means that collateralization is by no means a sufficient condition to attract financial capital. If senior creditors have no skills to run a complex project, and the pool of available substitute managers is not easy to find and competitive, collateral can lose much of its value in the event of failure, in which case mezzanine capital becomes indispensable.

In section 2 we discuss the pervasiveness of mezzanine finance in real estate investment. In section 3 we develop the theoretical model and in section 4 we present the bilateral arrangements between the parties. In section 5 we examine optimality of the contracts in section 4 . In section 6 we show that mezzanine finance is part of the optimal solution. In section 6 we discuss extensions, including heterogeneous operating skills and the role of screening in the presence of adverse selection. Section 8 concludes the paper.

\section{Mezzanine finance in real estate}

"If you've never owned and operated properties, you probably shouldn't be a mezzanine lender, because you're really not well positioned to take over properties." Bruce Batkin, CEO of Terra Capital Partners. 
Mezzanine finance is ubiquitous in commercial real estate where the typical capital structure involves a senior lender - often a large financial intermediary, pension fund or life insurance company - an entrepreneur and primary operator who provides the junior-most, common equity injection, and a mezzanine lender whose stake ranks between the senior lender and the owner. Mezzanine has become the primary form of intermediate (= neither juniormost nor seniormost) finance in commercial real estate, and its growth has fast outpaced that of second or preferred equity.

This motivating section has three distinct objectives. First, we argue that commercial real estate transactions are a natural interpretation of our model since: 1) they inherently contain significant asymmetric information such as unobservable effort on the part of the owner; 2) the foreclosure process that protects the senior claim is slow, onerous, prone to disputes and usually results in heavy losses for the lender; and 3) senior lenders tend to be institutions such as banks and insurance companies with limited expertise and operating capacities.

Second, we show that the most standard mezzanine contract in real estate is structured according to how our model suggests it should be. In particular, it provides for the expeditious conversion to asset ownership in the event of poor performance. This special feature is the key distinction between mezzanine and other intermediate finance alternatives.

Third, we provide direct evidence that, unlike senior lenders, mezzanine finance is provided by real estate specialists with operating capacities.

Figure 2 shows a schematic representation of a property purchase in real estate that involves mezzanine finance. Capital here comes from three different sources: equity from the mortgage borrower and owner of the property, a loan from the senior lender to the borrower and a mezzanine loan. Note that the mezzanine loan is issued not to the mortgage borrower but to a holding company that owns the mortgage borrower. The relation between the senior lender and the mortgage borrower is governed by two distinct documents. First, a promissory note stipulates all the obligations of the borrower including a detailed list of all promised payments but also all subsidiary obligations of the borrower, such as commitments to keep the property in good shape ("good repair clauses") or enter into insurance contracts for standard property hazards. Default occurs when any of the contracting clauses is violated. In the event of default, the promissory note contains acceleration clauses that give the senior lender the right to demand the entire loan balance by initiating a foreclosure sale process. The foreclosure on commercial real estate collateral is governed by specific mortgage laws that differ across 
Figure 1: Mezzanine Finance in Real Estate

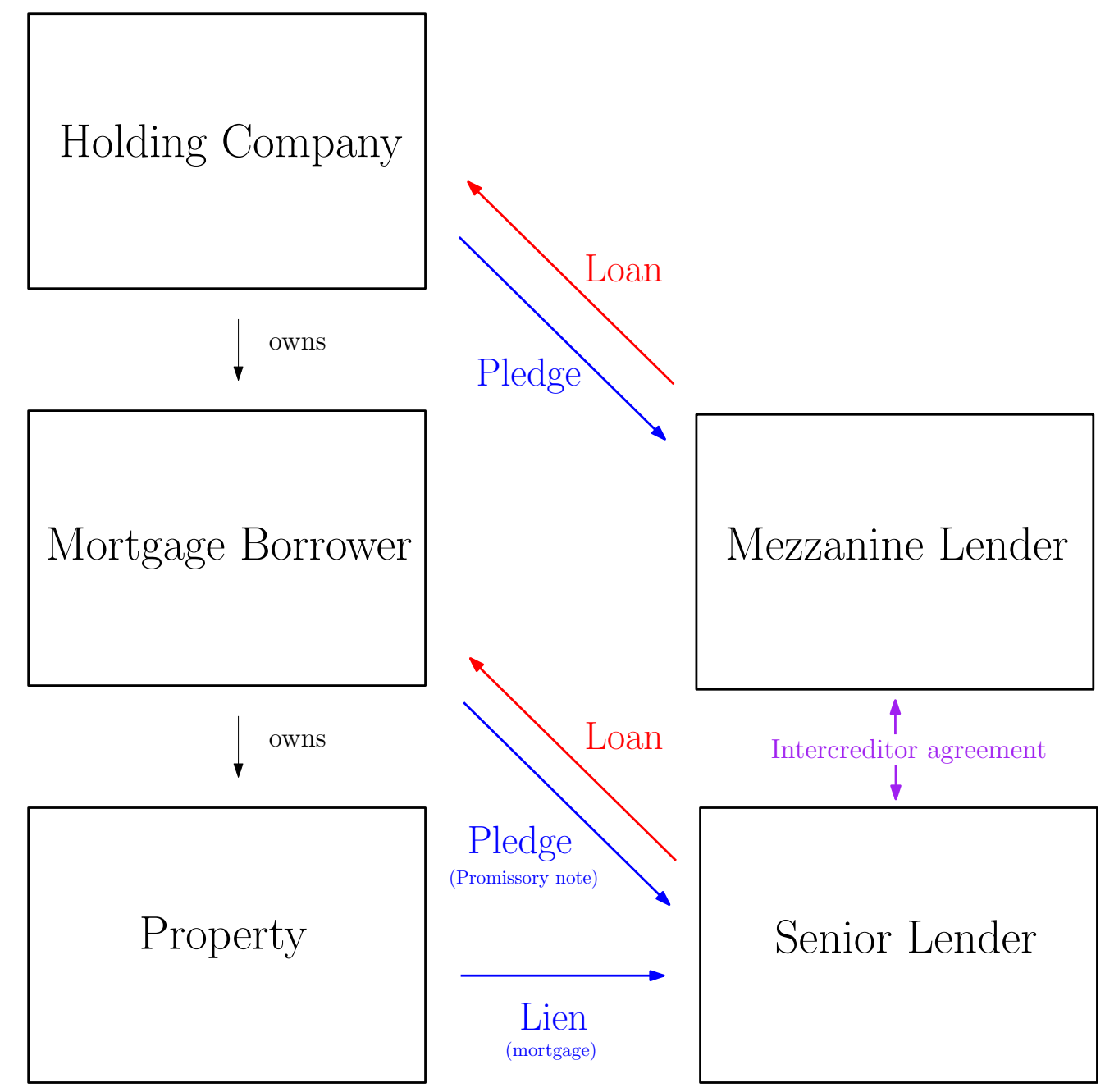


states, but typically provide for mandatory redemption periods and other borrower protections that make the acceleration process costly. As Gertler et. al. (2007, pp 398-99) discuss, it is not unusual for the foreclosure process to exceed one year, legal expenses alone can reach ten percent of the loan balance, and the borrower has limited incentives to spend on maintenance during the lengthy foreclosure process causing the property to deteriorate at a fast rate. These direct costs alone can amount to thirty five percent of the outstanding loan balance at the time of default. Mezzanine contracts in real estate usually stipulate specific payment obligations but, unlike mortgages, they are secured not by the property but by an equity interest in the entity or holding company that owns the real estate $!^{3}$ One key implication is that the mezzanine lender's collateral is usually treated as personal property rather than a general tangible claim under the relevant law, which results in the mezzanine lenders taking possession of the collateral under article 8 of the Uniform Commercial Code, an action that is markedly more expeditious (the process usually takes a few weeks at the most) and less costly than foreclosures under state mortgage laws. The efficiency of the collateral repossession not only distinguishes mezzanine finance from senior mortgages, but also separates it from other intermediate claims. For example, preferred equity owners do not have any foreclosure rights or specific collateral claims. In their case, recourse is so limited that promised dividend can be suspended by a vote of the board of directors without any risk that the holding company will be sued. Remedies for junior mortgage owners, for their part, fall under the same onerous mortgage laws as senior mortgages. Much worse from the position of senior lenders, junior lenders can trigger the highly costly foreclosure process when the borrower is delinquent regardless of the status of the first loan. Their presence further complicates and lengthens the default process and renders non-litigious dispute resolutions more difficult to achieve and subject to holdup problems..$^{4}$ From that point of view, mezzanine lenders are highly preferable since their foreclosure rights do not alter the senior lenders' resolution rights in any way.

The junior mortgage alternative is typically not even available for senior lenders who want to sell their loans to securitizers (banks that pool and repackage mortgages that are then passed through to investors). Precisely because of the associated risks for senior loans, rating agencies require additional subordination for senior tranches in collateral mortgage back securities (CMBS) pools of loans that are encumbered by second (junior) liens. Since securitizers seek to maximize the quantity of investment-grade securities they can extract from

\footnotetext{
${ }^{3}$ See Berman, 2013, for a detailed discussion of the legal framework that governs mezzanine finance in real estate.

${ }^{4}$ See Stein, 1997, for a detailed discussion.
} 
Table 1: Prominent private mezzanine lenders in the United States

\begin{tabular}{|c|c|c|c|c|c|}
\hline Firm & $\begin{array}{c}\text { Real Estate } \\
\text { specialist }\end{array}$ & $\begin{array}{c}\text { Owns } \\
\text { properties }\end{array}$ & $\begin{array}{c}\text { Sponsors } \\
\text { equity funds }\end{array}$ & $\begin{array}{c}\text { Operating } \\
\text { capacity }\end{array}$ & $\begin{array}{l}\text { Top Management has } \\
\text { operating background }\end{array}$ \\
\hline Everwest Real Estate Partners & $\checkmark$ & $\checkmark$ & $\checkmark$ & $\checkmark$ & $\checkmark$ \\
\hline Terra Capital Partners & $\checkmark$ & & & & $\checkmark$ \\
\hline Artemis Realty Capital & $\checkmark$ & & & & $\checkmark$ \\
\hline Ares & $\checkmark$ & & $\checkmark$ & & $\checkmark$ \\
\hline W Financial & $\checkmark$ & & & & $\checkmark$ \\
\hline Clarion Partners & $\checkmark$ & $\checkmark$ & $\checkmark$ & $\checkmark$ & $\checkmark$ \\
\hline AEW Capital Management & $\checkmark$ & $\checkmark$ & $\checkmark$ & $\checkmark$ & $\checkmark$ \\
\hline Lowe Enterprises Investors & $\checkmark$ & $\checkmark$ & $\checkmark$ & $\checkmark$ & $\checkmark$ \\
\hline NorthStar Realty Finance & $\checkmark$ & $\checkmark$ & $\checkmark$ & $\checkmark$ & $\checkmark$ \\
\hline Pearlmark Real Estate Partners & $\checkmark$ & $\checkmark$ & $\checkmark$ & $\checkmark$ & $\checkmark$ \\
\hline Square Mile Capital Management & $\checkmark$ & $\checkmark$ & $\checkmark$ & & $\checkmark$ \\
\hline Starwood Property Trust & $\checkmark$ & $\checkmark$ & $\checkmark$ & & $\checkmark$ \\
\hline Torchlight Investors & $\checkmark$ & & & & $\checkmark$ \\
\hline George Smith Partners & $\checkmark$ & & & & $\checkmark$ \\
\hline Apollo Commercial & $\checkmark$ & & $\checkmark$ & & $\checkmark$ \\
\hline Blackstone & $\checkmark$ & $\checkmark$ & & $\checkmark$ & $\checkmark$ \\
\hline Redwood-Kairos & $\checkmark$ & $\checkmark$ & & $\checkmark$ & $\checkmark$ \\
\hline Stonebeck Capital & $\checkmark$ & & & & $\checkmark$ \\
\hline Vornado & $\checkmark$ & $\checkmark$ & $\checkmark$ & $\checkmark$ & $\checkmark$ \\
\hline Harbor Group & $\checkmark$ & $\checkmark$ & $\checkmark$ & $\checkmark$ & $\checkmark$ \\
\hline SL Green & $\checkmark$ & $\checkmark$ & $\checkmark$ & $\checkmark$ & $\checkmark$ \\
\hline Sabra Healthcare REIT & $\checkmark$ & $\checkmark$ & $\checkmark$ & $\checkmark$ & $\checkmark$ \\
\hline ARC Realty Finance Trust & $\checkmark$ & & & & $\checkmark$ \\
\hline Strategic Realty Capital LLC & $\checkmark$ & $\checkmark$ & $\checkmark$ & $\checkmark$ & $\checkmark$ \\
\hline Ladder Capital & $\checkmark$ & & & & $\checkmark$ \\
\hline Rockwood Capital & $\checkmark$ & $\checkmark$ & $\checkmark$ & $\checkmark$ & $\checkmark$ \\
\hline Witkoff Group & $\checkmark$ & $\checkmark$ & $\checkmark$ & $\checkmark$ & $\checkmark$ \\
\hline LEM Capital & $\checkmark$ & $\checkmark$ & $\checkmark$ & $\checkmark$ & $\checkmark$ \\
\hline Dominion Mortgage Corporation & $\checkmark$ & & & & $\checkmark$ \\
\hline
\end{tabular}


mortgage pools, the underwriting standards they impose on conduit lenders usually prohibit junior loans. Such requirement affects portfolio managers as well since even banks who intend to maintain loans in their books want the option to sell the loans in the secondary market when the need arises. As a result, the volume of junior loans has fallen drastically since the mid-1990s in the United States. In sharp contrast, underwriting standards for conduit loans usually do not prohibit mezzanine loans since their presence does not affect the collateral rights of senior lenders in a significant way. Not surprisingly, and as Rubock (2007) has explained, as junior mortgage volumes have fallen, mezzanine volumes have risen. Whereas different mortgage liens interact and affect the value of each other's collateral claims, the foreclosure rights of mezzanine loans and senior loans do not intersect. As we will discuss at length in the next section, the presence of mezzanine loans actually protects the expected value of the senior loans in a number of fundamental ways.

The linchpin of the model we highlight below is the fact that the optimal contract calls for intermediate-seniority claim-holders with the ability to operate the property if the original owner underperforms. As the quote above illustrates, operating capacities are in fact viewed as a sine qua non feature of mezzanine providers. To document this more systematically, we compiled a list of the most prominent private providers of mezzanine financing in the United States.5 Since these are private corporations it is not possible to know for sure that the list contains all the largest private providers of mezzanine loans but conversations with top managers at prominent Mezzanine firms suggest that the list does in fact cover the immense majority of private mezzanine lending in the United States. The key question for us is whether these firms tend to have in-house or easy access to operating capacities. To answer that question we browsed the documentation those private firms make available online for direct evidence that 1) they operate properties, 2) top management has some background in real estate operations, 3) they own properties directly, which implies that, at the very least, they have relationship with operating partners in place, 4) they manage equity funds which, again, implies ties with operators or, finally, 5) that they are Real Estate specialists, unlike the typical financial intermediary that provides senior funding. As table 1 shows, all mezzanine providers on our list are Real Estate specialists and all are managed by executives that have some experience in operations. ${ }^{6}$ Most own properties directly or sponsor equity

\footnotetext{
${ }^{5}$ Publicly traded providers include chiefly listed Real Estate Investment Trusts - REITs - but those obviously have operating capacities. In fact, by law, most REIT assets must be real estate assets the lion share of their income must come from real estate.

${ }^{6}$ The online appendix provides specific documentation for each lender in the table.
} 
funds and majority of mezzanine lenders actually provide operating services to other investors. Mezzanine lenders, that is, are highly skilled investors.

\section{The environment}

Consider a world with three dates $t=0,1,2$ hence two periods, three agents, and an investment project that must be activated at date 0 in order to be productive. Agents 1 and 2 have an endowment $\epsilon \geqq 0$ of the unique good at date 0 while agent $P$, the "principal," has a unit endowment of the same good at date 0 . All agents can store their endowment and earn a risk-free gross return $R \geq 0$ at date 2 . The economy also contains a risky investment project that requires a one-time investment of one unit of the good at date 0 . The project needs to be operated either by agent 1 or by agent 2 in order to generate some output with positive probability. Agent $P$, on the other hand, cannot run the project. The project can be continued at date 1 at no additional capital cost but it can also be scrapped at that point for deterministic value $S \geq 0$.

If activated the project yields either nothing at date 1 or positive output $y_{H}>0$. The same holds at date 2 if the project is continued. Payoffs are i.i.d across periods. Let $\pi$ be the time-invariant probability of success in a given period. Agents 1 and 2 have an outside option that generates utility $V_{o} \geq 0$ in any period where they are idle (=not operating the project.) Making the outside option a utility gain rather than a physical payment makes the analysis easier (without losing much of economic interest) since agents cannot accumulate wealth as time goes by. All agents have linear preferences and do not discount the future.

Contracting between agents which we describe in the next section is limited by two fundamental frictions. First and foremost, only the agent who operates the project observes its output. In addition, the operator has the option to consume output unbeknownst to anyone, at a proportional cost $\phi \in[0,1]$. In other words, when they choose to secretly consume part $y$ of the project's output in any period they enjoy payoff $(1-\phi) y$. The cost proxies for the time and resources the operating agent has to spend in diverting funds.

The second friction is that the operator cannot commit ex-ante to operating the project at date 2 hence he must expect at least $V_{o} \geq 0$ in remaining payoff from any arrangement in order for the project to go on at date 1. The principal, for her part, can commit to any two-period arrangements.

If $\epsilon \geq 1$ the agents can operate the project alone and, in fact, it is optimal for them to 
do so. To focus on the more interesting case where the principal's contribution is needed, we assume throughout that $2 \epsilon<1$ so that even if they team-up and cooperate, the two agents cannot fund the project without the principal.

\section{Bilateral contracts}

Let's assume first that the principal can only work with one agent and gets to make a take it or leave it offer to that one agent. For concreteness, let agent 1 be the one agent involved in the contract. Any contract the principal offers the agent must promise at least lifetime utility $2 V_{o}$ at date 0 to the agent since he can turn down the contract. Furthermore, since the principal cannot observe output directly, she must rely on reports from the agent. A standard appeal to the revelation principle tells us that we can concentrate our attention without any loss of generality on direct revelation contracts. Specifically, we will call a contract the following list of objects:

1. An amount $k_{1} \leq \epsilon$ of capital contributed by the agent 1 and an amount $k_{P} \leq 1$ of capital contributed by the principal,

2. a payment schedule $\left\{w_{i}(h) \geq 0: i=1,2\right\}$ from the principal to the agent for all possible histories $h$ of cash flows at dates 1 and 2 , and,

3. scrapping probabilities $s(0), s\left(y_{H}\right)$ depending on the two possible output realizations in period 1.

Let $\mathcal{C}$ be the space of contracts $C=\left\{k_{1}, k_{P},\left\{w_{i}(h) \geq 0: i=1,2\right\}, s\right\}$ so defined. Note that we require all payments to the agent to be non-negative. This amounts to assuming that all capital injections to the project by the agent are made at date 0 , which is without loss of generality, since both parties are equally patient and the principal has the ability to commit to any payment arrangement, including the exchange of actuarially fair intertemporal transfers. The key observation here, and it will play a role in our main arguments below, is that the agents have finite resources and any monetary punishment is bounded above by the present value of these resources.

If $k_{1}+k_{P}<1$ then the project does not get off the ground an we will impose, without loss of generality, that in that case all payments to the agent are zero. Given a contract $C \in \mathcal{C}$ such that $k_{1}+k_{P} \geq 1$ hence such that the principal does choose to activate the project (why waste capital otherwise?), let: 


$$
V_{2}(y)=(1-s(y))\left[\pi w_{2}\left(y, y_{H}\right)+(1-\pi) w_{2}(y, 0)\right]+s(y) V_{0}
$$

denote the utility promised to the agent as of date 2 when output message $y \in 0, y_{H}$ is issued at date 1 , where $w_{2}$, the payment to the agent at date 2 , may depend on the output realization at date 2. Note that this reflects the fact that if he does not operate the project, the agent enjoys his outside option, and nothing more. For the agent to participate, we need:

$$
2 V_{o}+k_{1} R \leq \pi\left[w_{1}\left(y_{H}\right)+V_{2}\left(y_{H}\right)\right]+(1-\pi)\left[w_{1}(0)+V_{2}(0)\right]
$$

where, as stated in our definition of a contract, $w_{1}$ is the payment to the agent at date 1 and may depend on the first message. For direct revelation to be incentive compatible, we need:

$$
w_{1}\left(y_{H}\right)+V_{2}\left(y_{H}\right)>w_{1}(0)+V_{2}(0)+(1-\phi) y_{H}
$$

Indeed, the agent has the option to lie and divert output hence must be rewarded for telling the truth. That, as usual, imposes a minimal wedge between promised utilities and, in fact, that wedge can be so large that incentivizing the principal to tell the truth in the last period is not possible, hence the project must be shut down in period 2. When the project is continued with positive probability in period 2, i.e. for all $y \in 0, y_{H}$ such that $s(y)<1$, remaining expected payoffs must once again meet participation constraints:

$$
V_{o} \leq V_{2}(y)
$$

and incentive compatibility constraints

$$
V_{2}\left(y_{H}\right)>V_{2}(0)+(1-\phi) y_{H}
$$

Finally the principal's net payoff associated with the specific contract

$$
C=\left\{k_{1}, k_{P},\left\{w_{i}(h) \geq 0: i=1,2\right\}, s\right\} \in \mathcal{C}
$$


is, in tediously long form:

$$
\begin{aligned}
W(C)=\pi\left[\left(y_{H}+s\left(y_{H}\right) S-w_{1}\left(y_{H}\right)\right]\right. & +(1-\pi)\left[0+s(0) S-w_{1}(0)\right] \\
+(1-\pi)^{2}(1-s(0))\left[0-w_{1}(0,0)\right] & +\pi(1-\pi)\left(1-s\left(y_{H}\right)\right)\left[0-w_{1}\left(y_{H}, 0\right)\right] \\
+\pi^{2}\left(1-s\left(y_{H}\right)\right)\left[y_{H}-w_{2}\left(y_{H}, y_{H}\right)\right] & +(1-\pi) \pi(1-s(0))\left[y_{H}-w_{2}\left(0, y_{H}\right)\right] \\
& -k_{P} R
\end{aligned}
$$

The firm six terms of the above expression correspond to each of the six possible nodes at which the contract calls for a message from the agent to the principal and are weighted by the corresponding probabilities. For concreteness, we we will focus our attention on a specific part of the Pareto set, namely feasible contracts that maximize the principal's payoff ex-ante where we call a contract feasible if it satisfies conditions 4.1-4.4). We now turn to characterizing those optimal bilateral contracts.

\section{$5 \quad$ Optimal bilateral arrangements}

As usual maximizing the principal's objective is easiest done recursively. To that end, assume that the project hasn't been scrapped at date 1 and that the operator enters the final period with promised utility $V_{2} \geq V_{o}$. Write the highest payoff the principal can generate as of date 2 given $V_{2}$ as $W_{2}^{c}\left(V_{2}\right)$, where the superscript "c" reflects the fact the payoff is conditional on continuing the project in period 2 . This maximum payoff solves:

$$
W_{2}^{c}\left(V_{2}\right)=\max _{w_{L}, w_{H}} \pi\left(y_{H}-w_{H}\right)+(1-\pi)\left(-w_{L}\right)
$$

subject to:

$$
\begin{gathered}
\pi w_{H}+(1-\pi) w_{L}=V_{2} \text { (promise keeping) } \\
w_{H} \geq w_{L}+(1-\phi) y_{H} . \text { (truth telling) }
\end{gathered}
$$

and

$$
w_{H}, w_{L} \geq 0 \text { (limited liability) }
$$

Note, critically, that we write the promise-keeping as a strict inequality. In principle, the principal could always choose to deliver a higher date 2 payoff than any particular $V_{2}$. In fact, doing so may increase its own payoff as we will see below. But writing the promise 
keeping expression as a strict equality recognizes that the principal has the ability to commit to inefficient promises and actions at date 2. This paper is precisely about why the principal may want to commit to an ex-post inefficient action. As will become clear when we look at the ex-ante version of the problem, the answer is that doing so can make it cheaper to provide the right incentives to the agent over the life of the arrangement.

The optimal solution to the second period problem is easy to describe. Note that in terms of expected payoff the agent is willing to trade a decrease of $w_{L}$ of, say, $\delta>0$ in exchange for an increase of $\frac{\pi}{1-\pi} \delta$ in $w_{H}$. The principal's payoff is, likewise, unchanged. But doing those transfers weakens the truth telling constraint. Hence it follows that, optimally, $w_{L}=0$. This implies that $w_{H}=\frac{V_{2}}{\pi}$ is optimal if that turns out to be enough to meet the truth-telling constraint. Otherwise, the feasible set is empty. This appears to suggest that if she wishes to continue the project, the principal cannot commit to delivering less than $\pi(1-\phi) y_{H}$ in terminal utility following period 1's announcement. But, in fact, she has a broader set of options.

Recall that the principal has the option to scrap the project for a payoff of $S$ at the end of period 1. The associated value function is $W_{2}^{S}\left(V_{2}\right)=S+V_{O}-V_{2}$ since the principal gets $S$ from scrapping the project but must pay $V_{2}-V_{O}$ to the agent since they had promised $V_{2}$ but the agent can now get the outside option. If $S+V_{o} \geq \pi \phi y_{H}$ then scrapping is always optimal. Henceforth therefore we will focus on the more interesting case where $S+V_{O}<\pi \phi y_{H}$, so that scrapping is ex-post inefficient. In that case, scrapping only makes sense if the principal has committed to deliver less than $\pi(1-\phi) y_{H}$ to the agent. But, in fact, for $V_{2} \in\left(V_{0}, \pi(1-\phi) y_{H}\right)$ it is optimal for the principal to randomize between scrapping and not scrapping. More precisely, in the closure of that interval, the optimal scrapping probability is

$$
s\left(V_{2}\right)=\frac{\pi(1-\phi) y_{H}-V_{2}}{\pi(1-\phi) y_{H}-V_{0}},
$$

while it is zero everywhere else. The agent for his part gets a payoff of $V_{O}$ if the project is scrapped but $\pi(1-\phi) y_{H}$ otherwise. As a result, the overall remaining payoff to the principal following the first output announcement is:

$$
W_{2}\left(V_{2}\right)=s\left(V_{2}\right) S+\left(1-s\left(V_{2}\right)\right) W_{2}^{c}\left(\max \left\{V_{2}, \pi(1-\phi) y_{H}\right\}\right)
$$

This value function is concave, strictly increasing in the range $\left[0, \pi(1-\phi) y_{H}\right]$ and thereafter strictly decreasing with a slope of -1 , as depicted in figure 2 . 
Figure 2: Period 2 value function for the principal

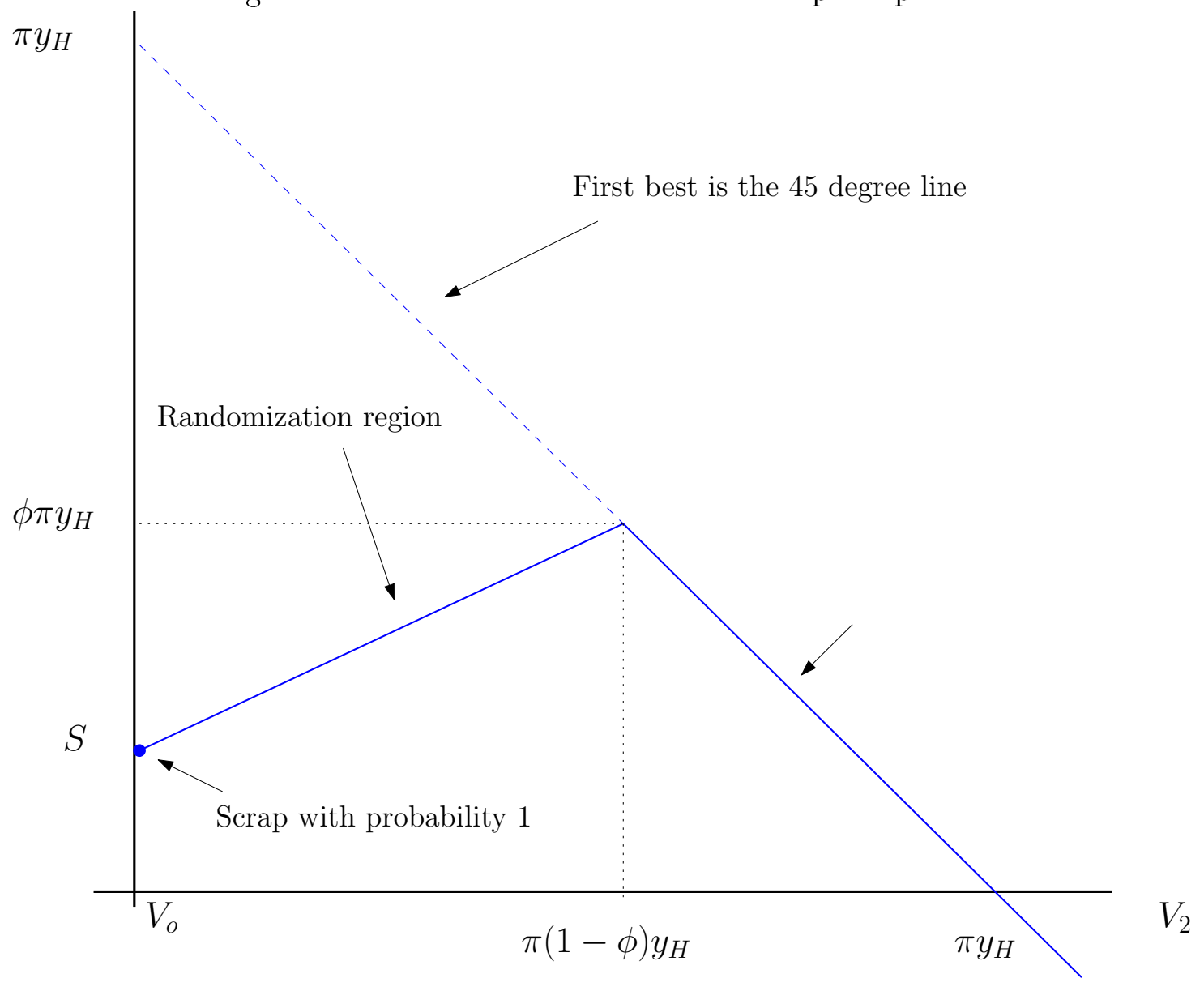


This analysis also implies that if $\phi=0$, it is not possible for the principal to profitably operate the project in the second period. In fact, and pointed out in a different context by Bulow and Rugoff (1989), this would remain true in the two-period case, and the project could not possibly get of the ground if $\phi$ were zero. Some direct punishment of default is necessary to support debt contracts when the principal and the agent are equally patient.

Now consider the recursive formulation of the principal's maximization as of date 1 given a promised utility $V_{1} \geq 2 V_{o}$. Given their initial investment $k_{P} \geq 0$, the principal's maximal payoff solves:

$$
W_{1}\left(V_{1} \mid k_{P}\right)=\max _{w_{L}, w_{H}, V_{H}, V_{0}} \pi\left[y_{H}-w_{H}+W_{2}\left(V_{H}\right)\right]+(1-\pi)\left[-w_{L}+W_{2}\left(V_{L}\right)\right]-k_{P} R
$$

subject to:

$$
\begin{gathered}
\pi\left[w_{H}+V_{H}\right]+(1-\pi)\left[w_{L}+V_{L}\right] \geq V_{1} \text { (promise keeping) } \\
w_{H}+V_{H} \geq w_{L}+V_{L}+(1-\phi) y_{H} \text { (truth telling) } \\
w_{H}, w_{0} \geq 0 \text { (limited liability) }
\end{gathered}
$$

and

$$
V_{H}, V_{L} \geq V_{O} \text { (lower bound on agent payoff at date 2) }
$$

Now assume that the project is continued (=not scrapped) with probability one, regardless of the earnings announcement, so that, in particular, $V_{L} \geq \pi(1-\phi) y_{H}$. Truth telling then implies that $w_{H}+V_{H}>\pi(1-\phi) y_{H}+(1-\phi) y_{H}$, so that, in turn, the expected payoff of the original agent must satisfy:

$$
\pi\left[w_{H}+V_{H}\right]+(1-\pi)\left[w_{L}+V_{L}\right] \geq \pi(1-\phi) y_{H}+\pi(1-\phi) y_{H}
$$

To preview the nature of the general solution to the principal's problem, assume that $V_{0}=$ $\epsilon=0 \leq \pi(1-\phi) y_{H}+\pi(1-\phi) y_{H}$ so that the agent needs only to be promised $V_{1}=0$ to participate. Then, given the inequality above, the principal's surplus under the policy of continuing no matter what earnings announcement is made is:

$$
W_{1}^{c}\left(V_{1}=0 \mid k_{P}\right)=\pi y_{H}+\pi y_{H}-\left[\pi(1-\phi) y_{H}+\pi(1-\phi) y_{H}\right]-k_{P} R
$$

The alternative policy is to scrap the project when a bad earnings announcement is made at 
date 1. The principal's highest surplus, in that case, is:

$$
W_{1}^{S}\left(V_{1}=0 \mid k_{P}\right)=\pi y_{H}+\pi^{2} y_{H}+(1-\pi) S-\pi(1-\phi) y_{H}-k_{P} R
$$

To understand this expression note that if the principal commits to scrap following a bad announcement the agent can make $w_{L}+V_{L}=0$ (this is the advantage of committing to a decision which is ex-post suboptimal) which means that truth telling only requires making $w_{H}+V_{H}=(1-\phi) y_{H}$ exactly as in the one period case. Note that when $\pi$ is sufficiently close to 1 so that committing to the value-destroying action is not too costly, the second policy dominates the first. The principal would commit to shut down the project in period 2 even though that destroys value ex-post. Clearly then, she would welcome a way to provide similar truth-telling incentives without destroying economic surplus. Note, in addition, that these two polar opposite policies are just two options the principal has at her disposal. She can also threaten the agent with scrapping with positive but not full probability. The following result provides a complete characterization of bilateral contracts that maximize the principal's surplus.

Proposition 5.1. The set of solutions to the principal's problem satisfies:

1. If and only if $W_{1}\left(V_{1} \mid 1-\epsilon\right)<0$ for all $V_{1} \geq 2 V_{o}+\epsilon R$ then the project is not funded, the principal simply stores the agent's contribution and the agents collects their outside options throughout;

2. Otherwise, a solution to the principal's problem exists such that $k_{1}=\epsilon, k_{P}=1-\epsilon$ and $V_{1}=2 V_{o}+\epsilon R$

3. If and only if $2 V_{o}+\epsilon R<\pi(1-\phi) y_{H}+\pi(1-\phi) y_{H}$ then all solutions satisfy $k_{1}=\epsilon$ and $k_{P}=1-\epsilon$;

4. The project is scrapped with positive probability if and only if

$$
\begin{aligned}
& \text { (a) } 2 V_{o}+\epsilon R<\pi(1-\phi) y_{H}+\pi(1-\phi) y_{H} \text {, and, } \\
& \text { (b) }-\pi+(1-\pi) \frac{\phi \pi y_{H}-S}{\pi(1-\phi) y_{H}-V_{o}}>0 \text {. }
\end{aligned}
$$

Proof. These results follow almost directly from the preceding discussion, with the exception of three important issues. First, the proposition says that it is at least weakly optimal for the 
agents to invest their entire endowment to the principal. This is because the principal can always store that endowment at the same rate as agents can and, furthermore, the principal can time the return to that investment is such a way as to make it as cheap as possible to provide truth-telling incentives to the agents.

Second, why does $2 V_{o}+\epsilon R<\pi(1-\phi) y_{H}+\pi(1-\phi) y_{H}$ imply that $k_{1}=\epsilon$ is necessary? Optimally, the principal seeks to promise as little as possible to the agent. If the contracts call for a continuation with probability one, she must offer $\pi(1-\phi) y_{H}+\pi(1-\phi) y_{H}$ anyway hence the principal can claim the agent's endowment and offer him an effective return that exceeds storage. Since that lowers $k_{P}$ strictly, the principal's payoff is strictly higher. If, on the other hand, the solution calls for scrapping with positive probability following a bad announcement then raising the agent's contribution allows for a one-for-one reduction in the principal's cost. The principal can deliver the additional ex-ante utility by raising $V_{H}$ and $V_{L}$ by the same amount. This, alone, would exactly offset the cost decrease in terms of the principal's payoff, but the increase in $V_{L}$ results in a lower probability of scrapping, hence a higher total surplus, leaving the principal strictly better off.

Third, the final item of the proposition says that scrapping is never optimal if the agent expects a utility level in excess of what is needed to run the project twice without the incentive compatibility constraint ever binding. When, on the other hand, the participation threshold is low, in the sense made precise in condition (a), threatening to scrap with positive probability is efficient when the slope of the randomization region is sufficiently shallow and the probability of a bad output realization in date 1 is sufficiently remote. To see why this is so, note first that we can set $w_{H}=w_{L}=0$ in period 1 without loss of generality since both the agents and the principal discount the future at the same rate. Then recall that continuing the project no matter what requires $V_{L} \geq \pi(1-\phi) y_{H}$ and, in turn, $\pi\left[w_{H}+V_{H}\right]+(1-\pi)\left[w_{L}+V_{L}\right] \geq$ $\pi(1-\phi) y_{H}+\pi(1-\phi) y_{H}$. That means, given condition (a) that the participation constraint has slack. Hence, at the most, $V_{L} \geq \pi(1-\phi) y_{H}$ since the principal has no reason to go beyond that. But does she have an incentive to go further? Doing so enables the principal to lower both $V_{H}$ and $V_{L}$ without violating the incentive compatibility constraint. Furthermore, this raises $\pi W_{2}\left(V_{H}\right)+(1-\pi) W_{2}\left(V_{L}\right)$ strictly as long as condition (b) is met. Indeed, the left-hand derivative of $W_{2}$ is $\frac{\phi \pi y_{H}-S}{\pi(1-\phi) y_{H}-V_{o}}$ at $\pi(1-\phi) y_{H}$ while it is -1 at $V_{H}>\pi(1-\phi) y_{H}$. This completes the proof.

Condition 3 of the proposition says that it is always optimal for the principal to require some skin-in-the-game on the part of agents, strictly so when incentive compatibility con- 
straints bind with positive probability as the contract unfolds. When condition (a) holds, note that some scrapping is always optimal when $\pi$ is near one. The threat to scrap if a bad message is issued is cheap to include in the contract in that case, because bad messages are unlikely. When (a) holds but (b) doesn't, no scrapping ever occurs along the contract path, but the principal is constrained to leave some rents on the table and allow the agent participation to be slack.

The back-up quarterback we introduce in the next section will create value for the principal either by erasing the risk of scrapping when both (a) and (b) hold, or by removing the

participation slack when (a) holds but (b) doesn't. In either case, the principal's expected payoff strictly rises.

Several interesting, testable implications for the optimal capital structure follow from item 3 in the above proposition.

Corollary 5.2. The minimal contribution by the original owner to the project (that is the lowest $k_{1}$ in the set of optimal allocations) increases strictly with project quality $(\pi)$ and falls strictly with the value of the outside option $\left(V_{0}\right)$ or the cost of misreporting $(\phi)$.

Put another way, more reputable (higher $\phi$ ) borrowers need to provide less skin-in-thegame, which makes intuitive sense. Likewise, if the borrower expects more compensation, incentive compatibility constraints are less likely to bind.

Less intuitive is the impact of project risk $(\pi)$ on the skin-in-the-game. To understand why safer project require more own equity injection at the optimal arrangement, note that it is only when the project is successful that incentives not to lie have to be provided. The safer the project, the more likely the operator will be in a position to lie.

\section{Back-up quarterbacks are essential}

Following the previous section, having a ready-replacement on stand-by once the project is activated makes intuitive sense: it becomes cheaper for the principal to provide truth-telling incentives. To formalize this, we first need to expand the contract space to the following set of objects:

1. An amount $k_{1} \leq \epsilon$ of capital contributed by agent 1 , an amount $k_{2} \leq \epsilon$ of capital contributed by agent 2 , and an amount $k_{P} \leq 1$ of capital contributed by the principal, 
2. An operator name $\left\{\kappa_{i}(x) \in\{1,2\}: i=1,2\right\}$ for all possible histories $x$ of messages at dates 0 and 1 , with the convention that $x=\emptyset$ at date 0 and the understanding that if an agent is not called upon to generate the project in a particular period, he generates his outside option utility,

3. a payment schedule $\left\{w_{i}^{j}(h) \geq 0: i=1,2, j=1,2\right\}$ for all possible histories $h$ of cash flows at dates 1 and 2 , and for each agent,

4. scrapping probabilities are $s(0), s\left(y_{H}\right)$, depending on the two possible output announcements in period 1.

Accordingly, we need to restate all subproblems. As before, it is at least weakly optimal to set $k_{1}=k_{2}=\epsilon$ and uniquely if an incentive compatibility may bind at some point in the contract. Let $V_{1}=V_{2}=2 V_{o}+\epsilon R$ be the participation thresholds of the two agents. It is straightforward to see that having the second agent in place affords the principal one more option, namely firing agent 1 at the end of date 1 if a bad announcement is issued and putting agent 2 in place. From the point of view of period 0, this means that, just like under the scrapping policy, the principal can set $w_{L}^{1}+V_{L}^{1}=V_{o}$, where the superscripts make it clear that these are promises made to the original operator. To deliver that lowest possible payoff to the agent in this case, the contract simply needs to call for agent 1 to remain idle in the last period, giving them $V_{L}^{1}=V_{o}$. As before, that means that $w_{H}+V_{H}=(1-\phi) y_{H}+V_{o}$ is feasible and optimal when it is sufficient to deliver $V_{1}$. In fact, it is clearly optimal to set $V_{H}=(1-\phi) y_{H}+V_{O}$, so that the promise can be used not only to provide the correct incentives in period 1 but, since the payment is then withheld to date 2 , the same one-and-only payment also gives the right incentives in period 2 if agent 1 is still in place. If a bad announcement is made, then agent 1 is replaced, leaving the principal to deal with agent 2 on a one-period basis. In that case it is optimal for the principal to promise exactly $\min \left\{\pi(1-\phi) y_{H}, V_{2}-V_{o}\right\}$. Indeed, agent 2 has already received inalienable utility $V_{o}$ from being on the sidelines in period 1 , leaving $V_{2}-V_{o}=V_{o}+\epsilon R$ to deliver. The principal delivers this promise and no more, if this is high enough for the incentive compatibility constraint to be slack or, in the other case, delivers $\pi(1-\phi) y_{H}$, the bare minimum required for truth-telling to be feasible.

At the end of the day and under that strategy, the ex-ante surplus of the principal is:

$$
\begin{aligned}
W_{1}^{\text {BackupQB }}\left(V_{1} \mid k_{P}=1-2 \epsilon\right) & =\pi y_{H}+\pi y_{H}-\max \left\{\pi\left[(1-\phi) y_{H}+V_{0}\right], 2 V_{o}+\epsilon R\right\} \\
& -(1-\pi) \max \left\{\pi(1-\phi) y_{H}, V_{o}+\epsilon R\right\}-(1-2 \epsilon) R
\end{aligned}
$$


To understand this expression, note that now the project is continued no matter what, so the expected output is $\pi y_{H}+\pi y_{H}$. On the other hand, the payoff to agents is $\left[(1-\phi) y_{H}+V_{0}\right]$ delivered to agent 1 if the project succeeds in period 1 and $\min \left\{\pi(1-\phi) y_{H}, V_{o}+\epsilon R\right\}$ delivered to agent 2 if the project fails in period 1 . Now the key result is:

Proposition 6.1. The maximal payoff $W_{1}^{\text {BackupQB }}\left(V_{1} \mid k_{P}=1-2 \epsilon\right)$ the principal can generate with a back-up quarterback in place exceeds all payoffs she can generate dealing with only one agent, strictly so if and only if $2 V_{o}+\epsilon R<\pi(1-\phi) y_{H}+\pi(1-\phi) y_{H}$.

Proof. As discussed in the previous section, when $2 V_{o}+\epsilon R \geq \pi(1-\phi) y_{H}+\pi(1-\phi) y_{H}$ the principal can commit to let the project run for two periods, and incentive compatibility constraints are slack. In that case:

$$
W_{1}^{c}\left(V_{1}=2 V_{o}+\epsilon R \mid k_{P}=1-\epsilon\right)=\pi y_{H}+\pi y_{H}-\left[2 V_{o}+\epsilon R\right]-(1-\epsilon) R,
$$

and that cannot be improved upon. Therefore, in that case, back-up QBs are not essential. So consider now the case where $2 V_{o}+\epsilon R<\pi(1-\phi) y_{H}+\pi(1-\phi) y_{H}$. Then, once again using the same arguments as in the previous section:

$$
W_{1}^{c}\left(V_{1}=2 V_{o}+\epsilon R \mid k_{P}=1-\epsilon\right)=\pi y_{H}+\pi y_{H}-\left[\pi(1-\phi) y_{H}+\pi(1-\phi) y_{H}\right]-(1-\epsilon) R
$$

We need to supplant this payoff with the back-up QB approach. Now $2 V_{o}+\epsilon R<\pi(1-$ $\phi) y_{H}+\pi(1-\phi) y_{H} \Longrightarrow V_{o}<\pi(1-\phi) y_{H}$ so that, in particular,

$$
\max \left\{\pi\left[(1-\phi) y_{H}+V_{0}\right], 2 V_{o}+\epsilon R\right\}<\pi(1-\phi) y_{H}+\pi(1-\phi) y_{H}
$$

Furthermore and by the same logic, $V_{o}+\epsilon R<\pi(1-\phi) y_{H}+\epsilon R$ so that

$$
\max \left\{\pi(1-\phi) y_{H}, V_{o}+\epsilon R\right\}<\pi(1-\phi) y_{H}+\epsilon R \text {. }
$$

But this implies that

$$
\begin{aligned}
\max \left\{\pi\left[(1-\phi) y_{H}+V_{0}\right], 2 V_{o}+\epsilon R\right\} & -(1-\pi) \max \left\{\pi(1-\phi) y_{H}, V_{o}+\epsilon R\right\} \\
& <<\pi(1-\phi) y_{H}+\pi(1-\phi) y_{H}+\epsilon R
\end{aligned}
$$


so that

$$
W_{1}^{\text {BackupQB }}\left(2 V_{o}+\epsilon R_{1} \mid k_{P}=1-2 \epsilon\right)>W_{1}^{c}\left(V_{1}=2 V_{o}+\epsilon R \mid k_{P}=1-\epsilon\right) .
$$

We have established that when $2 V_{o}+\epsilon R<\pi(1-\phi) y_{H}+\pi(1-\phi) y_{H}$ the backup QB strategy dominates the strategy with one agent, and a commitment by the principal to continue the project no matter what. Does this also dominate all strategies with one agent where scrapping occurs with positive probability? For that strategy to be better than continuing no matter what, we need conditions (a) and (b) of the previous proposition to hold. In period 2, agent 1 receives a convex combination of $V_{0}$ and $\pi(1-\phi) y_{H}$ in date 2 following a bad announcement while the principal generates the same convex combination of $S$ and $\pi \phi y_{H}$. Write the exact same contract with a back-up QB in place but replace the scrapping with hiring a new agent, and the principal's surplus is strictly higher, since $\pi \phi y_{H}>S$.

\section{Extensions}

\subsection{Heterogeneous operating skills}

The model assumes that the two agents with operating ability are equally skilled and is thus silent about which should optimally serve as the original owner. A simple way to break this tie is to think of each project as an idea that is generated by one of the two agents and from which that agent can exclude the other agent until the contract is violated. Alternatively, we could introduce different level of operating skills. In that case, the optimal allocation would obviously call for the most skilled agent to be the primary owner while the backup quarterback is not quite as skilled but still creates more value than a foreclosure would generate. Realistically, ranking the quality of the skills of two agents is not at all obvious when it comes to new projects. Even well known and reputable operators might fail when they encounter a new situation, a development in a different culture, geographic area or with unique operating dynamics. What this means is that when projects are developed by wellknow operators, themselves mezzanine investors in many other projects, senior lenders should demand mezzanine finance from a different operator. Furthermore, as we have shown before, the safer the project the more skin-in-the-game is required, because a normally well regarded

and safe operator has higher incentives to lie. When the measure of safeness $(\pi)$ is linked to ability, senior lenders can face fewer but still large disasters if they do not have a back-up quarterback in place. Put another way, the arguments we have outlined above do not hinge 
in any way on the assumption that agents 1 and 2 are equally skilled.

\subsection{Adverse selection}

Our model focuses on moral hazard frictions between the senior lender and original operators. Obviously, since they are not specialists, in general senior lenders may not be able to screen projects as effectively as real estate specialists can. Assume for instance that when our economy begins, projects look like as we have described above but that there are good and bad operators. With some positive probability the "idea" generated by agent 1 is a dud that generates no cash-flows. While agents 1 and 2 can tell good projects from fantasies, senior lenders cannot tell the difference. Obviously, if the frequency of fantasies is high enough and if limited liability prevents the senior lender from punishing dud providers harshly, the project can't be funded under bilateral arrangements. But the presence of mezzanine lenders mitigates this issue as long as their skills enables them to screen projects more effectively than senior lenders. This is easiest seen in the extreme case where mezzanine lender can tell good projects from bad perfectly. Then senior lenders need only announce that they will fund projects if and only if mezzanine lenders are willing to come on board to fully solve the adverse selection problem. While we have abstracted from the screening role of mezzanine finance in our analysis above, the fact that mezzanine lenders are skilled specialists obviously serves to mitigate both adverse selection and moral hazard problems in practice. This is the core idea of our paper: some stakeholders create value by providing skills in a delegated fashion to generalists stakeholders. The optimal way is when those skills come packaged with financial capital. This provides a good explanation for the puzzling fact that mezzanine lenders often provide insignificant slivers of capital in a deal (it's not unusual for mezzanine funds to account for less than $5 \backslash \%$ of all capital.) What they bring to the table is their skills as much as if not more so than their funds. [Insert Tom's story from Texarkana mall here.]

\section{Conclusion}

Mezzanine loans have increased at a fast pace in the last decade. In particular, they have skyrocketed in commercial real estate but also in large mining projects. A common explanation links mezzanine finance with one more layer of debt filling the gap between senior debt and equity. This reasoning is at best incomplete. It ignores the fact that junior B-notes have 
been declining while mezzanine debt has been on the rise. On the surface, it appears that the preference for mezzanine debt lies in its very weak form of collateral. Indeed, subordinate debt, claims of service providers and taxes all trump the collateral rights of the mezzanine lender. But this confuses the interests of mezzanine financiers with those of standard creditors. Contrary to other lenders, mezzanine finance is not primarily interested in the collateral of the other lenders. If that were the case, both mezzanine lenders and other creditors would be worse off. The reason is that unsecured debtholders actively participate in the intercredit negotiations in debt restructurings following bankruptcies, and their agreement must be secured if the firm is to be reorganized and continue. The space for disputes and protracted negotiations would escalate with more complex securities in the balance sheet. Differently, mezzanine lenders collateral does not touch the collateral rights of the senior and junior lenders, for mezzanine lenders care about priority and perfect their security interest by taking control rights of the entity (LLC, or partnership) that operates the assets. Interest in LLCs and partnerships are deemed "general intangibles" under the Uniform Commercial Code, and UCC foreclosures are much swifter than mortgage foreclosures. However, swift resolution is not guaranteed simply by the existence of statutory requirements under the bankruptcy code. More important to ensure continuation is the rapid turnover of new operators with the ability to move the project forward with minimum disturbance.

Our analysis establishes that with limited commitment by the owner, there are instances when senior creditors fund the project only when mezzanine finance is willing participate. Mezzanine finance provides expertise in the form of human capital to operate the project in case the owner is terminated. In this sense mezzanine finance works as a backup quarterback. It can do so because mezzanine lenders have the right to take over the operating entity and do not touch the senior creditors' claim to the physical assets.

We show that the optimal contract requires the commitment of mezzanine investors to coinvest in the project, and that their claim is debt with a trigger to convert into equity if they have to step in and manage the project. The requirement by the senior creditors that mezzanine investors put down capital up-front makes the mezzanine contract different from the alternative course of action of searching for replacement if later the project's operator fails. In return, senior creditors agree ex-ante not to exercise any liens they have on the assets. Without such commitments by both parties the contract would not be different from the typical contract where upon termination, senior creditors fire the current entrepreneur/manager and hire a new agent. 
Our analysis was performed to explicitly address the issue of moral hazard. It would be straightforward to analyze the case of adverse selection, when entrepreneurs/owners market different "ideas" to creditors. Then the backup quarterback mezzanine financier is called to perform an additional role, that of screening. However, rating agents suffer from incentive problems as well, as the recent financial crises has shown $]^{7}$ This is yet another reason to require participation. However, it would be impractical to ask money from an agent who simply acts as a screener, and consequently the best arrangement comes when the screener is able to play an active role in the execution of the project, which is precisely what mezzanine finance accomplishes.

\footnotetext{
${ }^{7}$ In February 2015, S\&P agreed to pay $\$ 1.4$ billion to settle charges that it issued inaccurate credit ratings on investments tied to mortgages between 2004 and 2007.
} 


\section{References}

Berman, A., 2013. Mezzanine Debt and Preferred Equity in Real Estate, in Alternative Investments: Instruments, Performance, Benchmarks, and Strategies, John Wiley \& Sons, Chapter 9 .

Biais, B., G. Plantin, and J. Rochet, 2007. Dynamic security design: Convergence to continuous time and asset pricing implications, Review of Economic Studies, 74, 345-390.

Bolton, P., and D. Scharfstein, 1990. A Theory of Predation Based on the Agency Problems of Financial Contracting, American Economic Review, 80, 93-106.

Brennan M., and E. Schwartz, 1978. Corporate Income Taxes, Valuation, and the Problem of Optimal Capital Structure, Journal of Business, 51, 103-14.

Bulow, J., and K. Rogoff, 1989. Sovereign Debt: Is to Forgive to Forget? American Economic Review, 79, 43-50.

De Marzo P., and M. Fishman, 2007. Optimal Long-term Financial Contracting, Review of Financial Studies, 20, 2079-128.

De Marzo P., and Y. Sannikov, 2006. Optimal Security Design and Dynamic Capital Structure in a Continuous Time Agency Model, Journal of Finance, 61, 2681-724.

Gârleanu N., and J. Zwiebel, 2009. Design and Renegotiation of Debt Covenants, Review of Financial Studies, 22, 749-781.

Goldstein R., N. Ju and H. Leland, 2001. An EBIT-based Model of Dynamic Capital Structure, Journal of Business, 74, 483-512.

Hart O., and J. Moore, 1994. A Theory of Debt Based on the Inalienability of Human Capital, Quarterly Journal of Economics, 109, 841-79.

Hart O., and J. Moore, 1998. Default and Renegotiation, Quarterly Journal of Economics, 113, 1-41.

Miller, M., 1977. Debt and Taxes, Journal of Finance, 32, 261-76.

Modigliani, F., and M. Miller, 1958. The Cost of Capital, Corporation Finance, and the Theory of Investment, American Economic Review, 48, 261-97.

Myers S., 1977. The Determinants of Corporate Borrowing, Journal of Financial Economics, $5,147-75$.

Myers S., and N. Majluf, 1984. Corporate Financing and Investment Decisions when Firms have Information that Investors Do not Have, Journal of Financial Economics, 13, $187-225$. 
Rauh, J., and A. Sufi, 2010. Capital Structure and Debt Structure, Review of Financial Studies, 23, 424-80.

Regmington K., and J. Pollack, 2008. Tools for Complex Projects, Gower, London.

Roberts, M., and A. Sufi, 2009. Renegotiation and Financial Contracts: Evidence from Private credit Agreements, Journal of Financial Economics, 93, 159-84.

Spear, S., and C. Wang. 2005. When to Fire a CEO: Optimal Termination in Dynamic Contracts, Journal of Economic Theory, 120, 239-56.

Stein, J. 1997. Subordinate Mortgage Financing: The Perils to the Senior Lender, Real Estate Review, Fall issue, 3-9. 